\title{
Стратегия передачи слов-реалий в переводе на португальский язык рассказа И.С. Тургенева «Хорь и Калиныч» из цикла «Записки охотника»*
}

\author{
Мария Михайловна Мазняк** \\ Ольга Сергеевна Фомина夫夫夫
}

Аннотация: В статье анализируются способы передачи с русского языка на португальский культурномаркированных слов - реалий на примере текста И.С. Тургенева «Хорь и Калиныч». Приводится краткая история создания цикла «Записки охотника», а также ретроспективная история его переводов на иностранные языки.
Abstract: This article considers the transference ways of the culturallymarked words - realia - from Russian to Portuguese in Ivan Turgenev's Khor and Kalinych. A brief history of the collection Notes from a Hunter's Album as well as a retrospective history of its translations into foreign languages are given.

Ключевые слова: реалия; перевод; Тургенев; эквивалентность; русский язык; португальский язык; аналог.

Keywords: realia; translation; Turgenev; equivalence; Russian language; Portuguese language; analogue. 


\section{1. О цикле И.С. Тургенева «Записки охотника»}

* Artigo submetido em 22 de fevereiro e aprovado em 27 de fevereiro de 2018.

** Кандидат филологических наук, старший преподаватель кафедры романской филологии Филологического факультета Санкт-Петербургского

Государственного Университета, постоянный член CompaRes. Основная сфера деятельности: португальский модернизм, поэтика, фонетика португальского языка, постколониальный дискурс, перевод. mmmazniak@mail.ru.

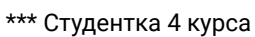
португальского отделения кафедры романской филологии Филологического факультета Санкт-Петербургского Государственного Университета, fomina.olga96@gmail.com.
В 1847 году в некрасовском «Современнике» появился «Хорь и Калиныч» - первый очерк из «Записок охотника», который принёс Тургеневу широкую известность. Разнообразию содержания цикла соответствует богатство жанровых форм: бытовой очерк, рассказ, психологическая новелла, «картинка с натуры», лирический этюд, пейзажная зарисовка - все эти жанры, проникнутые философскими размышлениями, оказались равно доступны писателю, сумевшему внести свой вклад в развитие русской новеллистической прозы.

Обстоятельства появления на страницах литературного журнала рассказа «Хорь и Калиныч» были описаны Тургеневым в воспоминаниях: «Только вследствие просьб И.И. Панаева, не имевшего чем наполнить отдел "Смеси» в 1-м нумере "Современника», я оставил ему очерк, озаглавленный "Хорь и Калиныч"»1. Возможно, что подзаголовок «Из записок охотника» был сознательно дан Панаевым с целью привлечь читателя к весьма распространённому в 30-40-е годы XIX века жанру охотничьих рассказов. Возможно, также, что смысл «внешнего» для рассказа названия носит более глубинный и более обобщённый смысл. Охотник может восприниматься как сторонний, почти беспристрастный и одновременно заинтересованный наблюдатель, наделённый даром глобального созерцания, подмечающего даже самые мелкие детали; он - очевидец, свидетель, летописец, является одновременно и своеобразным проводником между персонажами и читателем. Почти все встречи охотника с героями рассказов цикла происходят почти случайно: в поисках ночлега, хороших охотничьих мест, по пути, но всегда эти встречи - неожиданные открытия как для рассказчика, так и для читателя. Известный

\footnotetext{
1 Тургенев И.С. Записки охотника; Повести и рассказы. М.: Худож. лит., 1979. С. 11.
} 
литературный критик В.Г. Белинский пророчески определил творческую судьбу Тургенева: «Вы и сами не знаете, что такое «Хорь и Калиныч», - писал критик автору. - Судя по «Хорю», Вы далеко пойдёте. Это Ваш настоящий род...»².

«Записки охотника» создавались Тургеневым в атмосфере намеченного в ряде европейских литератур эстетического, или точнее, неэстетического переосмысления действительности, нашедшего своё отражение в движении к «низам» общества, к народу, к простому человеку, что не раз отмечал Белинский: «настоящий род таланта Тургенева физиологический очерк разных сторон русского быта и русского люда».

Художественный принцип «физиологического очерка» - подчёркнутая достоверность изображения - совпадал с самой природой таланта Тургенева: рисовать с натуры. С первой же страницы рассказа «Хорь и Калиныч» читатель вовлекается в привычное для «физиологического очерка» рассуждение о том, чем отличается мужик Орловской губернии от мужика Калужской губернии. Автор специально сопоставляет два основных психологических типа - и именно это делает сюжетом очерка. Мужики предстают здесь как некие объекты изучения, достойные самых скрупулёзных, детализированных описаний (внешности, уклада жизни, воззрений и т.п.) Его образы большей частью имели реальные прототипы, их отдельные черты автобиографичны, в языке много этнографических «эссенций»4.

Сохранились многочисленные мемуарные свидетельства о существовании реальных прототипов тургеневских героев из «Записок охотника». Так, реальным лицом был знаменитый Хорь, мужик, «наделённый государственным умом» и «лбом Сократа». Известно, что А.А.

\footnotetext{
2 там же. С. 574.

3 там же. С. 7.

${ }^{4}$ Тургенев И.С. Записки охотника; Повести и рассказы. М.: Худож. лит., 1979.
} 
Фет записал свои впечатления от встречи с этим русским крестьянином, которого обессмертил Тургенев:

В запрошлом году, в сезон тетеревиной охоты мне привелось побывать у одного из героев тургеневского рассказа «Хорь и Калиныч». Я ночевал у самого Хоря. Заинтересованный мастерским очерком поэта, я с большим вниманием всматривался в личность и домашний быт моего хозяина. Хорю теперь за восемьдесят лет, но его колоссальной фигуре и геркулесовскому сложению лета нипочём ${ }^{5}$.

Эта книга принесла Тургеневу всемирную славу. Вскоре после выхода в свет первого отдельного издания «Записки охотника» получили известность в Европе и Америке. Первые переводы «Записок охотника» стали появляться уже в 50-е годы XIX века во Франции, Германии, Англии, затем Дании и других европейских странах.

Интересна судьба переводов «Записок охотника». Первый перевод цикла на французский язык вышел в самом начале войны 1854 года и явился скорее не пропагандой русскоязычной культуры, а орудием политической борьбы. Тургенев, не удовлетворённый не только качеством перевода, но и политической ситуацией, возникшей в связи с выходом первого французского издания, выступил с открытым письмом, в котором выразил свой протест. Но даже этот далеко не блестящий перевод заставил французских писателей обратить внимание на автора «Записок охотника» - и в первую очередь Проспера Мериме, ставшего впоследствии не только популяризатором творчества Тургенева во Франции, но и другом русского писателя. В 1858 году во Франции вышел перевод «Записок охотника», выполненный Ипполитом Делаво, одним из лучших славистов того времени. Перевод был сделан при непосредственном участии самого Тургенева. Это единственный авторизованный перевод «Записок охотника», что и значится на титульном листе книги: «единственное издание, авторизованное автором».

\footnotetext{
5 там же. С. 579.

${ }^{6}$ Тургенев И.С. Записки охотника; Повести и рассказы. М.: Худож. лит. С. 582.
} 
В Германии переводы рассказов из «Записок охотника» начали появляться уже в 1849 году, то есть значительно раньше, чем в других странах Европы. Однако известность и популярность «Записок охотника» среди немецких читателей утвердилась с середины 50-х годов, после выхода в свет двухтомного издания в переводе Августа Видерта, который был также одним из лучших интерпретаторов этих произведений для европейского сознания.

Английские читатели впервые познакомились с рассказами из «Записок охотника» в 1855 году на страницах популярного в то время журнала "Household Words" («Вседневное слово»), редактором которого был Чарльз Диккенс.

Несколько позже возник интерес к произведениям Тургенева в Америке. Одним из популяризаторов писателя был литературный критик Томас Перри, много писавший о Тургеневе ещё в 70-х годах XIX в. Именно Ceверная Америка эпохи аболиционизма была особенно открыта гуманистическому голосу писателя за освобождения крепостных крестьян.

Отметим также, что переводы «Записок охотника» появлялись во второй половине XIX века на датском языке, откуда началось их распространение по скандинавским странам; ещё при жизни Тургенева «Записки охотника» были переведены на финский языкт; отдельные рассказы цикла переводились на славянские языки Восточной Европы.

В истории переводов на зарубежные языки русской художественной прозы ранним переводам «Записок охотника» также принадлежит весьма важное место: их многочисленность и наличие ряда близких по времени повторных переводов того же русского текста, выполненных разными лицами, позволили сразу же сделать подробные сопоставления этих переводов в пределах одного или даже нескольких языков (немецкие, фран-

7 Отметим, что в это время Финляндия входила в состав Российской Империи. 
цузские и английские переводы «Записок охотника» появились почти одновременно) и тем самым глубже проникнуть в существо русского оригинала; обилие критических отзывов и рецензий, вызванных этими изданиями, ещё более способствовало возможности на основе изучения этих переводов сделать некоторые важные теоретические обобщения - о первоклассных качествах русского литературного языка, о лучших способах его передачи средствами иностранной речи. Тургенев пристально и с большим вниманием следил за всеми этими переводами, сверял их с русским текстом, давал советы переводчикам, протестовал против допущенных ими искажений. В результате основные европейские литературы едва ли не в первый раз получили образцовое произведение русской художественной прозы в наиболее близком к оригиналу виде. Последствия этого и для самого Тургенева и для судьбы за рубежом русского художественного слова были очень значительны.

В издание 1874 года вошли двадцать пять рассказов, и с тех пор состав «Записок охотника» никогда больше не менялся.

В середине XIX века «Записки охотника» были уже широко распространены во всех странах Европы. С тех пор критическая литература об этом произведении Тургенева росла повсеместно; множились также и переводы книги на всё возраставшее количество языков.

\section{2. Слова-реалии и особенности их перевода}

Проблема непереводимости оригинального текста всегда была и остаётся актуальной для теории и практики перевода. Реалии как безэквивалентная лексика, представляют собой особую трудность при переводе не в последнюю очередь потому, что они являются абсо- 
лютно привычными для языка оригинала и абсолютно непривычными для языка перевода. Под «реалией» часто понимают «предмет», «вещь», «понятие» или «явление», характерное для истории, культуры, быта, уклада того или иного народа, не встречающееся у других народов. Вариативность номинаций, входящих в понятие «реалия», сводятся к одному обобщающему определению - реалия синонимична самому понятию «жизнь», а следовательно, отражает не только бытовые и культурные проявления определённого народа в определённую эпоху, но и имплицитно ориентируется на психологию читателя подлинника.

Понятие «перевод реалий» довольно условно, поскольку реалии, как правило, непереводимы, но, несмотря на это, могут быть переданы на другой язык. Основные трудности при передаче реалий сводятся к следующему: 1) реалия, как правило, не имеет эквивалента в переводящем языке из-за отсутствия у его носителей предмета или явления, обозначаемого этой реалией и 2) необходимость, наряду с предметным значением, передать национальную и историческую окраску данной реалии. «Переводчики избирают разные способы перевода реалий в зависимости от того, насколько значительную функцию выполняет тот или иной знак-реалия для поэтики переводимого текста»8. Поэтому если переводчику удастся максимально точно передать слова-реалии, найти удачный эквивалент, им будет достигнута одна из необходимых целей художественного перевода - создание текста, обладающего одинаковой с подлинником способностью эстетического и эмоционального воздействия на читателя.

В фокус внимания настоящей статьи попадает рассказ «Хорь и Калиныч» из цикла И.С. Тургенева «Записки охотника» в переводе на португальский язык Иринеу Франку Перпетуу, изданного в 2013 в Издательстве 34 в

\footnotetext{
${ }^{8}$ Гарбовский Н.К. Теория перевода. М.: Издательство Московского университета, 2007. C. 483.
} 
Бразилии. В начале рассказа «Хорь и Калиныч» читаем следующее: «Орловский мужик невелик ростом, сутуловат, угрюм, глядит исподлобья, живёт в дрянных осиновых избёнках, ходит на барщину, торговлей не занимается, есть плохо, носит лапти.... ${ }^{9}$. Второе предложение - то есть начало рассказа - как камертон, задаёт тон всему произведению и представляет читателю «полный набор» типичных атрибутов жизненного уклада Орловской губернии. В этом русском сообщении можно обнаружить сразу четыре реалии: социально-классовая - мужик, государственно-административного устройства - барщина, этнографические - избёнка, лапти. Эти узнаваемые слова становятся не просто вокабуляром описания крестьянского русского быта, но, в силу, частотности их употребления, приобретают символическое значение для читателя-рецепиента. Этот рассказ, по праву можно назвать эмблематичным произведением данного цикла и наиболее «узнаваемым» произведением для многих поколений русскоязычных читателей. Известный английский прозаик Джордж Мур, встретившийся с Тургеневым в 1878 году, писал в своих воспоминаниях о новаторском характере «Записок охотника»: «При чтении их литература понимается нами как нечто совершенно новое, так как они совершенно новы по форме и содержанию и не имеют в прошлом никаких корней... Это не жизнь плюс художник, это просто жизнь....110.

\section{3. Способы перевода реалий в рассказе И.С. Тургенева «Хорь и Калиныч»}

3.а. Описательный перевод. Транскрипция/ транслитерация с пояснением переводчика.

\footnotetext{
${ }^{9}$ Тургенев И.С. Записки охотника; Повести и рассказы. М.: Худож. лит., 1979. С. 27.

${ }^{10}$ там же. С. 584.
} 
Транскрипция/транслитерация - один из наиболее распространённых, по-своему "лёгких», а часто единственно-возможных способов передачи на язык перевода реалий языка оригинала. Этот способ сохраняет графический облик и звучание оригинального слова и оба эти компонента уже сами по себе становятся основными маркерами, позволяющими читателю произведения на языке перевода увидеть и услышать отличное от его культуры явление. Встречающиеся в рассказе слова-реалии как «мужик», «телега», «изба», «самовар», «балалайка», «староста» зафиксированы в авторитетном словаре Dicionário HOUAISS da Língua Portuguesa: "mujique", "telega", "isbá", "samovar", "balalaica", "estaroste". Например: «И хорошо, батюшка, делаешь; стреляй себя на здоровье тетеревов да старосту меняй почаще», ("No que faz muito bem, meu pai: atire à vontade nos tetrazes e troque de estaroste com mais frequência"), где в уста Хоря вложена мысль о необходимости перемен.

Однако, некоторые реалии в рассказе уже вышли из употребления и представляют собой сложность не только для иностранного, но и для русскоязычного читателя, относящегося к другому поколению. Для этого требуются пояснения, которые часто берёт на себя переводчик, являясь в полном смысле слова проводником информации между автором и читателем.

1.«Кроме немногих ракит, всегда готовых к услугам, да двух-трёх тощих берёз, деревца на версту кругом не увидишь...».

1.a. "Tirando uns salgueiros sempre às ordens e umas duas ou três bétulas ralas, não se vê uma árvore sequer no raio de uma versta...".

Встречающаяся в данном примере верста - русская единица измерения расстояния, равная, примерно, 1,07 км - остаётся при переводе без изменений, однако переводчик добавляет уточняющий комментарий в сноске: "Medida russa equivalente a 1,07 km". Величина версты 
неоднократно менялась ввиду относительно неточного измерения самой метрической единицы, однако неизменная близость её значения к 1 км сохранила употребительным слово и в современном разговорном русском языке, придав ему метафорическое значения большого и чаще всего пустого расстояния. Сохранение оригинальной формы данной единицы измерения расстояния "versta" представляется оправданным, так как существующая в португальском языке единица измерения "légua", используемая до введения в оборот метрической системы, равна $6,600 \mathrm{~m}$ в Бразилии и $5,572 \mathrm{~m}$ в Португалии ${ }^{11}$, то есть, значительно больше русского аналога.

2. «В этой конторе я продал купцу Аллилуеву четыре десятины лесу за выгодную цену».

2.a. "Nesse escritório, vendi ao negociante Allilúiev quatro deciatinas de floresta por um bom preço".

Ещё одна встречающаяся реалия, требующая пояснения. Десятина - старая русская мера измерения площади. Первоначально десятина измерялась двумя четвертями и представляла собой квадрат со сторонами в 1/10 версты. Для современного читателя данная реалия требует пояснение. В книге находим пояснение переводчика: "Antiga medida agrária russa, equivalente a 1,09 ha".

3. «... а приезжим торгашам, которые, за неимением безмена, считают пуд в сорок горстей...».

3.a. "... mas para negociantes forasteiros, os quais, por falta de balança, contam um pud como equivalente a quarenta mãos...".

Встречающиеся в данном примере единицы меры представляют некоторую трудность как для переводчика, так и для иноязычной читательской аудитории. В этом предложении собраны сразу две разноплановые реалии, обозначающие единицы измерения массы: «пуд» и «горсть». Первая из них - пуд - устаревшая единица

11 Dicionário eletrónico HOUAISS da Língua Portuguesa. - CD-ROM - Serial - DHS21571925. 
измерения массы русской системы мер, равный, примерно, 16 кг. Данная реалия не переводится, а транслитерируется, и поясняется в сноске: "Medida russa antiga igual a 16,3 kg”. Следующая реалия - горсть - может быть охарактеризована как «народное» измерение объёма чего-либо, представляющего собой сложенную ладонь в форме временного вместилища, и измерения вещества, удерживаемого в ней. Эта реалия переведена более широким по значению словом "та̃о" - «кисть», «рука», что, тем не менее, не искажает его значения. Смысл высказывания призван сориентировать читателя на том, что приезжие торгаши обманывают крестьян, так как сорок горстей вряд ли может соответствовать 16 кг пуда.

Упомянутые в этом же предложении простейшие весы - безмен - заменены более универсальным по значению словом "balança".

4. Да принеси нам квасу».

4.a. "E nos traga kvas".

Типичный славянский кислый напиток - квас - остаётся в неизменном виде при переводе, а в сноске переводчик даёт лаконичное пояснение: "Refresco fermentado de pão de centeio".

5. «... бегал за дрожками...».

5.a. “... corria atrás da drójki...”.

Безусловно требует пояснения и реалия «дрожки» лёгкая четырёхколесная открытая повозка для коротких поездок: “Carruagem leve, aberta, de quatro rodas”.

Следует остановиться ещё на одном примере.

6. « - Попал Хорь в вольные люди, - продолжал он вполголоса, как будто про себя, - кто без бороды живёт, тот Хорю и на́больший».

6.a. " - Se Khor estivesse entre os livres - prosseguiu, como que só para si - , todo mundo que não tivesse barba seria maior do que Khor". 
Данная фраза требует пояснения не только для португалоязычных, но и для отечественных читателей. В примечании В. Фридлянда поясняется: «Намёк на чиновническую власть, который не избежать крестьянину, даже освободившемуся от крепостной зависимости (чиновники по указу Николая I от 2 апреля 1837 г. не имели права носить усы и бороду)»"12. Об этом говорится и в примечании переводчика: "Alusão ao funcionarismo público. Devido a um decreto do tsar Nicolau I, de 1837, os funcionários públicos estavam proibidos de usar barba e bigode".

К реалиям здесь можно отнести упомянутый указ императора Николая I, восходящий, также к известной реформе Петра I. Пафос данного высказывания - в критике современного Тургеневу социального и административного устройства, в котором крестьянин остаётся зависимым, «униженным и оскорблённым» даже после фактического и юридического освобождения от крепостной зависимости. В этом размышлении Хоря спрятана критика и, возможно, пессимизм Тургенева относительно принципиальных изменения сложившейся ситуации в ближайшем будущем.

3.b. Описательный экспликативный перевод

Экспликативный способ перевода, при котором раскрытие значения лексической единицы исходного языка при помощи дополнительных вербальных средств, развёрнутых словосочетаний, раскрывающих существенные признаки обозначаемого данной лексической единицей явления, по праву считается громоздким и неэкономным. Однако нередко именно этот вариант необходимо применить переводчику для адекватной передачи встречающейся в оригинале безэквивалентной лексики. Часто переводчики прибегают к сочетанию нескольких приёмов - транскрипции или калькированию, описательному переводу и экспликативной инфор-

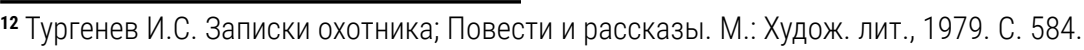


мации, дав последнюю в сноске или в комментарии. Это даёт возможность сочетать краткость и экономность средств выражения, свойственных транскрипции, с раскрытием семантики данной единицы, достигаемой через описательный перевод.

7. «На наличные деньги он берёт рубль двадцать пять копеек - полтора рубля ассигнациями; в долг - три рубля и целковый».

7.a. "À vista, ele aceita um rublo e vinte e cinco copeques em moedas, mais um rublo e meio em notas; a crédito, três rublos em nota, e mais um em moeda".

В приведённом примере содержится конкретная информация, связанная с денежными величинами. При переводе переводчик прибегает к минимальным пояснениям, которые вставляет в текст произведения. В первом примере переводчик восполняет информацию, не выраженную в тексте оригинала: «двадцать пять копеек» - "vinte e cinco copeques em moedas", то есть монетами, что коррелируется с экспликационным добавлением далее - "em notas", то есть, банкнотами, что, в свою очередь, является переводом слова «ассигнации», означающего бумажный денежный знак в России с 1769 по 1843 гг. Выбор такого решения перевода представляется оправданным, так как, во-первых, уравновешивает денежные понятия, встречающиеся в тексте в рамках одной фразы и, во-вторых, облегчает восприятие фразы при переводе.

8. «Да, в прошлом году гривенник пожаловал».

8.a. "Sim, no ano passado deu uma moeda de dez copeques".

Гривенник - серебряная монета достоинством в десять копеек. Именно это определение было выбрано в качестве переводческой перифразы для передачи денежной единицы. Переводчик сделал выбор в пользу передачи смысла, то есть факта, что в прошлом году помещик Полутыкин пожаловал Калинычу десять копеек. 
9. «Я уж ему не раз говорил: «Откупись, Хорь, эй, откупись!..».

9.a. "Já lhe disse mais de uma vez: "Compre sua liberdade, Khor, compre...".

10. « - Послушай-ка, Хорь, - говорил я ему, - отчего ты не откупишься от своего барина?»

10.a. " - Escute, Khor - disse-lhe - , por que você não compra a sua alforria do patrão?"

Тексты «Записок охотника» И.С. Тургенева иногда опосредованно, иногда непосредственно поднимают вопрос существования формы крепостного права в России. Повелительная форма «откупись», являясь редуцированной формой «откупись от барина», буквально «выкупи себя», «выкупи себе свою свободу» понятна читателю, знакомому с историей России. В первом примере переводчик решает добавить пояснение: "Compre sua liberdade...", то есть, «купи свою свободу». Во втором примере переводчик также прибегает к экспликации данного понятия, однако делает это на «бразильский» манер. Вместо слова "свобода" употребляется "alforria", желая "приблизить» восприятие текста к культурному фону реципиента.

Разница в переводе одного и того же по семантике высказывания кроется в личности говорящего. Первая фраза вложена в уста помещика Полутыкина, барина, хозяина крепостных крестьян, среди которых оказывается и Хорь. Здесь переводчик поясняет глагол «откупись» родовым понятием «свобода» ("liberdade"), что придаёт разговору неформальный оттенок. Вторая фраза - это замечание самого рассказчика, охотника, человека стороннего. Употреблённое здесь в качестве экспликации слово "alforria" приобретает анафорическое значение и синонимично понятию «вольная». Это юридическое понятие придаёт беседе более формальный оттенок двух незнакомых людей. 


\section{3.d. Аналоговый перевод}

Нередко переводчику необходимо подыскивать в переводящем языке аналог для иноязычной реалии, знакомый реципиенту. Часто в роли функционального аналога выступают подходящие для сравнения предметы, а также единицы измерения, принятые в стране переводящего языка. Применение перевода этого типа в ряде случаев может вызвать и местные ассоциации.

11. «Посреди леса, на расчищенной и разработанной поляне, возвышалась одинокая усадьба Хоря».

11.a. "Em meio à floresta, em uma clareira limpa e bem cuidada, a casa de Khor se erguia, solitária".

Анафорическое понятие «усадьба» заменено родовым понятием "a casa" - «дом».

12. «... сошёлся я в поле и познакомился с одним калужским мелким помещиком».

12.a. "... eu me deparei com o campo e travei conhecimento com um pequeno proprietário de Kluga...".

Помещик - владелец поместья в России с конца XV - до начала XX вв. Имущественное положение помещиков было неоднородно. Основным показателем их финансовой состоятельности в первой половине XIX века было душевладение. К мелким помещикам относились владельцы от 21 до 100 душ. В данном случае переводчик выбирает существительное "proprietário», буквально означающее: «que ou aquele que detém a posse legal de um bem imóvel, de terra, fábrica, casa comercial, banco, empresa de prestação de serviços etc» ${ }^{13}$. Содержание передано верно, однако при первом упоминании теряется понятный русскоязычному читателю смысловой акцент на лежащий в основе принцип расчёта финансовой состоятельности Полутыкина - владение крепостными крестьянами-душами.

${ }^{13}$ Dicionário eletrónico HOUAISS da Língua Portuguesa. - CD-ROM - Serial - DHS21571925. 
13. «.. духом сомчи: барина везёшь».

13.a. "... vá a toda: você está levando o patrão".

Барин - человек из привилегированных классов (помещик, дворянин). Слово «барин» также употреблялось как форма обращения зависимых людей к представителям высших сословий. Для перевода выбрано слово "patrão», что, наш взгляд, является удачным так как сразу устанавливает иерархию взаимоотношений персонажей.

14. «Я вам стану оброк платить хороший».

14.a. "Vou pagar ao senhor um ótimo tributo".

Следующая реалия - оброк - оказывается более сложной для рецепции иностранными читателями. Оброком называлась одна из форм повинности зависимых крестьян, которая заключалась в уплате помещику своеобразной дани в денежном или продуктовом выражении. Частноправовая практика функционирования оброка позволяет рассматривать его, в широком смысле, как разновидность налога. Этот принцип заложен в выборе переводчиком аналогичного слова в португальском языке - «tributo».

15. «Теперь он мне сто целковых оброка платит...».

15.a. "Agora ele me paga um tributo de cem rublos...".

Встречающаяся здесь реалия «целковый» означает старинную серебряную монету достоинством в один рубль. Замена более архаичной номинации более современной и стилистически нейтральной, на наш взгляд, уместна, так как для смысла фразы важнее оказывается номинал денежной единицы, чем ещё номинация.

16. «Баба мужику слуга».

16.a. "A mulher é a serva do homem".

В данном примере реалия «мужик» переводится на португальский язык, а не воспроизводится, как в других 
случаях, несмотря на то, что в оригинале употребляется одно и тоже слово: « - Скажите, пожалуйста, - спросил я Полутыкина за ужином, - отчего у вас Хорь живёт отдельно от прочих ваших мужиков?» ( " - Diga, por favor - perguntei a Polutikin, no jantar - , por que Khor vive isolado dos outros mujiques?"). Гипонимическая замена в данном случае оправдана, так как здесь слово «мужик» несёт в себе родовое значение "мужчина», «муж» и противопоставляется значению «женщина», «баба». Эта разница, контекстуально и имплицитно понятная русскоязычному читателю, передаётся при переводе словом "homem", имеющим родовое понятие и противопоставленное понятию "mulher". Одновременно с этим антонимичное понятие «баба» передаётся с помощью родового понятия "mulher", то есть гендерная оппозиция «мужик» - «баба», характерная для разговорного русского языка, передаётся стилистически нейтральными "homem" - "mulher". Смена регистра сохраняет смысл высказывания.

17. «За несколько медных грошей баба отдаёт «орлу» не только всякую ненужную тряпицу, но часто даже мужнину рубаху и собственную паневу».

17.a. "Por alguns tostões de cobre, a mulher vende à "águia" não apenas todos os trapos inúteis, como, muitas vezes, até mesmo a camisa do marido e sua própria saia".

Встречающаяся здесь денежная единица - медный грош - столь привычная русскоязычному читателю имеет более сложную этимологию. В России монеты для оборота с обозначением номинала в грошах официально никогда не чеканилась, однако в силу эквивалентности двух серебряных копеек грошу в XVI-XVII веках, монеты в две копейки и получили название «гроша» и такое название стало общеупотребительным термином и зафиксировано в литературных памятниках и исторических документах. Выбранный для перевода эквивалент - tostão - оправдан и уместен, так как одно 
из его первых значений - «moeda de níquel (no Brasil) ou de prata (em Portugal) equivalente a 100 réis» ${ }^{14}$ - в полной мере отражает значение.

Следующая бытовая реалия - панёва, или понёва означает женскую шерстяную юбку замужних женщин из нескольких кусков ткани с богато украшенным подолом - передаются при помощи гипонимического перевода, где в качестве эквивалента выбирается более широкое по значению слово "saia" - «юбка». Перевод представляется оправданным для современного читателя, хотя в данном случае теряется существенная деталь - панёва - верхняя юбка, сшитая из добротной ткани. Отдать такую юбку за «копейки» - скорее всего, необдуманный и весьма расточительный поступок. Конечно, панёва непонятна и современным русскоязычным читателям рассказа Тургенева, однако её «ценность» раскрывается в противопоставлении «всякой ненужной тряпицы». При переводе этот нюанс потерян, однако общий смысл фразы сохранён.

18. «Сейчас, батюшка, сейчас, - раздался голос со двора, - лапоть подвязываю».

18.a. "Já vou, meu pai, já vou", soou uma voz que vinha do pátio, "estou amarrando as alpargatas".

Одна из самых узнаваемых реалий русского крестьянского быта наряду с избой, самоваром и балалайкой лапти - плетёная из лыка или бересты низкая обувь, охватывающая только стопу. Несмотря на национальный колорит данного слова, разновидность такой обуви встречалась и у других народов, в том числе, у североамериканских индейцев и австралийских аборигенов. Вместо привычного в данном случае приёма транслитерации, переводчик заменяет «лапти» на схожий элемент «alpargatas».

${ }^{14}$ Dicionário eletrónico HOUAISS da Língua Portuguesa. - CD-ROM - Serial - DHS21571925. 
19. «... между брёвнами и по косякам окон не скиталось резвых прусаков...».

19.a. "... nos troncos e no umbral da janela, não havia carochas ligeiras a perambular...".

Следующая интересующая нас реалия - наименование в просторечии рыжих тараканов «прусаками», происходящее от мнения, что этот вид насекомых попал в Россию из Пруссии. Такая деталь требует отдельного пояснения. При выборе слова переводчик остановился на более общем значении «carocha» = «barata», означающим «таракан». Возможно, замена слова эквивалентом более общего значения связана с фактом существования разных типов тараканов, в том числе и в Латинской Америке.

\section{4. Заключение}

В заключении можно сделать вывод, что при передаче слов-реалий в художественном тексте немаловажным становится прагматический подход: необходимость правильно понять предложенную языком оригинала реалию, проанализировать её важность для контекстуального выражения, и затем определить способ её передачи на иностранный язык, принимая во внимание психологию читателя-рецепиента. В проанализированном тексте рассказа переводчику удаётся соблюсти баланс разных способов передачи культурно-маркированной лексики подлинника (транскрипция, транслитерация, калькирование, описание, пояснение), и одновременно передать настроение оригинального текста Тургенева, сохранить его смысл и звучание на португальском языке. 


\section{Библиография}

ГАРБОВСКИЙ, Н.К. Теория перевода. М.: Издательство Московского университета, 2007.

ТУРГЕНЕВ, И.С. Записки охотника; Повести и рассказы. М.: Худож. лит., 1979.

HOUAISS, A. Dicionário HOUAISS da Língua Portuguesa. - CD-ROM - Serial - DHS-21571925.

TURGUÊNIEV, Ivan. Memórias de um caçador. / Tradução, posfácio e notas de Irineu Franco Perpetuo. - São Paulo: Editora 34, 2013. 